\title{
Spatiotemporal Symmetry and Trend Assessment of Ms $\geq 7.0$ Earthquakes in the Sichuan-Yunnan Region of China
}

\author{
Jia Wan ${ }^{1,2, *}$, Junping Yan ${ }^{1}$ and Xiaomeng Yan $^{1}$ \\ ${ }^{1}$ School of Geography and Tourism, Shaanxi Normal University, Xi'an 710119, China \\ ${ }^{2}$ North Minzu University, Yinchuan, Ningxia 750021, China
}

\begin{abstract}
Commensurability information, a butterfly diagram and a commensurability structure system were used to analyse the spatiotemporal symmetry and to assess the trends of $\mathrm{Ms} \geq 7.0$ earthquakes in the Sichuan-Yunnan region of China. The results show that the next earthquake may occur in 2020 or 2021, as seismic signals are strong. Analysing the characteristics of epicentre spatial migration, there is a significant synchrony and symmetry between the latitudinal and longitudinal epicentre migrations. The symmetry axis is $30^{\circ} \mathrm{N}$ in latitude and $101.5^{\circ} \mathrm{E}$ in longitude. There is a northeast-southwest strike symmetry axis, and the next epicentre may migrate toward the southwest (i.e., south of $30^{\circ} \mathrm{N}$ and west of $101.5^{\circ} \mathrm{E}$ ); the calculated strike symmetry axis is $\mathrm{Y}=3.5 \mathrm{X}-329$. By grouping earthquake disaster events, the spatial migration pathways of the epicentres regularly exhibit jump-migration and sequential-migration. The migration distributions over the symmetry axis quadrants are 'uniform-discrete' and 'concentrated-dispersion'.
\end{abstract}

\section{Introduction}

In the context of global change, the occurrence of major natural disasters has begun to occur more frequently in some areas and cause greater losses than in recent history. Strengthening the ability to predict and forecast major natural disasters is a basic necessity for adapting to global change and for realizing sustainable regional development [1]. More than 5 million earthquakes occur globally every year, causing numerous casualties and secondary disasters, such as tsunami, landslides, fires and plagues. As earthquakes cause the greatest number of fatalities, they are regarded as the most serious among the natural disasters in the world.

China is located between the Circum-Pacific Belt and the Alpide-Himalayan Belt, and is one of the countries that is the most seriously impacted by earthquake disasters worldwide. Pushed by the Pacific Plate and the Indo-Australian Plate, seismic fault zones are fully developed in China [2]. Since the 20th century, more than 800 earthquakes with surface-wave magnitudes (Ms) $\geq 6$ have occurred across all provinces in China, except for Guizhou, Zhejiang and Hong Kong. As many as 600,000 people have died, accounting for $50 \%$ of global earthquake fatalities [3]. With the advancement of urbanization, urban losses and social disasters caused by earthquakes are becoming more serious and prominent. Therefore, it is very important to study the trends in earthquake occurrences, and thereby contribute to disaster prevention and mitigation.

Earthquake prediction is a scientifically difficult problem worldwide, as there is no effective method for accurately predicting all earthquakes. During the 1980s,
Wen proposed an information forecasting theory, which is based on commensurability in astronomy, and developed the theory and application for disaster forecasting [4]. Some advances have been made in assessing the trends of natural disasters using information forecasting theory [5-10], and the reported accuracy of such trend predictions has reached $61.5 \%$ [11]. Considering the convenience and uniformity of disaster prevention and mitigation, an administrative division, the Sichuan-Yunnan region of China, was selected as the region of interest in this study. Commensurability calculations, butterfly diagrams and a commensurability structure system were used to study $\mathrm{Ms} \geq 7$ earthquakes in the Sichuan-Yunnan region, with an emphasis on the regularity of their distributions and the likely trends to develop in the future. It is expected that such research will provide a basis for reference so that relevant departments may actively address earthquake disasters and reduce the associated social and economic losses.

\section{Study area and methods}

\subsection{Regional description}

The Sichuan-Yunnan region is located in the southwest of China, where the geologic environment is complex and seismic activity is high (Fig. 1). The SichuanYunnan block consists of the Sichuan-Yunnan outer arc zone and the western Yunnan inner arc zone. The outer arc zone is a first-order tectonic boundary zone; the main body includes the Yushu-Xianshuihe-Xiaojiang fault

\footnotetext{
* Corresponding author: wanjia3963@126.com
} 
system, while the inner arc zone is located on the eastern edge of the Tibetan Plateau, which extends southward from the Litang Fault to the Nanting River Fault, and regional tectonic deformation is pronounced [12,13]. More than $120 \mathrm{Ms} \geqslant 6$ earthquakes have occurred in this region since the start of the 20th century, accounting for $15 \%$ of the total number throughout China. A severe Ms 8.0 earthquake hit Wenchuan, Sichuan at 14:28 CTT on 12 May 2008, injuring 374,643 people, killing 87,149 people and directly causing an economic loss of 845.1 billion yuan ( $\sim 94.9$ billion pounds). Landslides, debris flows, barrier lakes and other secondary disasters, which are rare globally, also occurred. Qin et al. suggested that since 2010, the region has entered a new period of seismic activity, reminding us once again that it is necessary to determine the trends of earthquake disasters in order to protect both human lives and property [14].

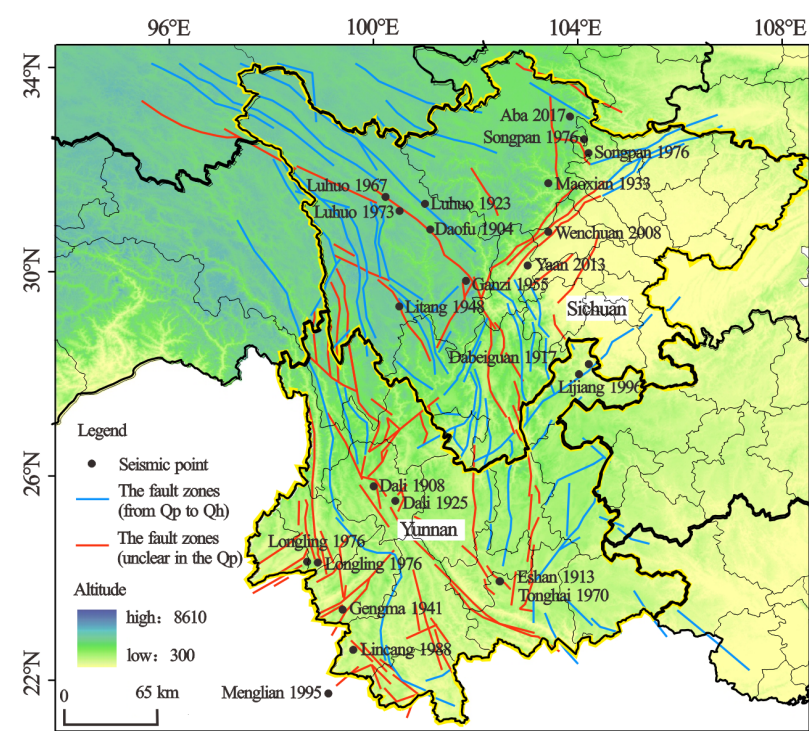

Fig. 1. Active tectonic map of the Sichuan-Yunnan region in China.

\subsection{Data sources}

The seismic data used in this study, which span the period from 1900-2010, are from the Global Earthquake Catalog [15]. Seismic data from 2011-2017 are from the China Earthquake Networks Centre (CENC; 2018). The relative numbers of monthly sunspot activity are from the National Centers for Environmental Information (NCEI; 2018).

\subsection{Methods}

\subsubsection{Commensurability information}

Commensurability is an expression of the cyclical expansion of natural orders. It is a mixing hypothesis of the superposition of cycles of different lengths and an expression of the principles that can jointly measure the elements of one system [16]. The basic principle here is that disaster events and abnormal signals have a relational expression in time series. When the frequency of the established relational expression is higher, it is assumed that the relational expressions can reflect an inevitable cycle. Commensurability relational expressions include ternary, quarternary and pentabasic commensurability, which can be used to calculate the timing of the next disaster event by using the time series of a previous disaster event. The ternary commensurability relational expression is $\mathrm{Xd}=\mathrm{Xa}+\mathrm{Xb}$ $\mathrm{Xc}, \mathrm{a}+\mathrm{b}-\mathrm{c}=\mathrm{d}$. The relational expression for quarternary commensurability is $\Delta \mathrm{X}=\mathrm{Xa}+\mathrm{Xb}-\mathrm{Xc}-\mathrm{Xd}, \mathrm{a}+\mathrm{b}=\mathrm{c}+\mathrm{d}$. If the year in which the next disaster event will occur is denoted as $\mathrm{Xi}$, and the year in which the last disaster event occurred is $\mathrm{Xj}$, then $\mathrm{Xi}=\mathrm{Xj}+\Delta \mathrm{X}$. Finally, the pentabasic commensurability relational expression is $X f=X a+X b+X c-X d-X e, f=a+b+c-d-e$.

\subsubsection{Butterfly diagram}

A butterfly diagram is a time series combination that includes 4 years and 2 sets of cycles. Butterfly diagrams use equal time intervals used to reflect the time symmetry of disaster events. By constructing a relationship of the year structure, more than two groups of butterfly diagrams with temporally symmetrical characteristic can be drawn [17]. The predicted year can then be determined, and a random probability and prediction confidence level can be calculated. The random probability of a butterfly diagram is $\mathrm{T}=\mathrm{M} / \mathrm{N}$, and the prediction confidence level is $(1-\mathrm{a})=\mathrm{M} /(\mathrm{N}+1)$, where $\mathrm{T}$ is the probability of the predicted year in the time series of disaster events, $\mathrm{N}$ is the total number of disaster events and $M$ is the number of events involved in the actual forecast.

\section{Temporal symmetry and trend assessment}

\subsection{Commensurability calculations}

Extracting the year of earthquake occurrence information from Table 1, there were $24 \mathrm{Ms} \geqslant 7$ earthquakes in the Sichuan-Yunnan region over the last 117 years. Four earthquakes occurred in 1976, and they were recorded as one earthquake in the time series. The results were calculated using time-sequence groups according to the commensurability relational expressions presented in section 2.3.1.

Using a command in which X1=1904, X2=1908, $X 3=1913, X 4=1917, X 5=1923, X 6=1925, X 7=1933$, $X 8=1941, X 9=1948, X 10=1955, X 11=1967, X 12=1970$, $X 13=1973, X 14=1974, X 15=1976, X 16=1988, X 17=$ 1995, X18=1996, X19=2008, X20=2013, X21=2017 and $\mathrm{X} 22$ is the year in which the next earthquake will occur, the commensurability can be calculated according to the annual time series. The ternary commensurability relational expression is $\mathrm{X} 22=\mathrm{Xm}+\mathrm{Xn}-\mathrm{Xp}$, such that $m+n-p=22$. The ternary commensurability results are as follows: earthquakes occurred 13 times in 2021, 9 times in 2023, 7 times in 2024, 7 times in 2026, 6 times in 2018, 6 times in 2020, 6 times in 2028, 6 times in 2029, 
6 times in 2032, 5 times in 2027, 5 times in 2030, 4 times in 2022, 3 times in 2019 and 3 times in 2025.

Table 1. Catalogue of Ms $\geq 7.0$ earthquakes in the SichuanYunnan region over the last 117 years.

\begin{tabular}{|c|c|c|c|c|c|}
\hline No. & Date & Epicent & e location & Magnitude & Locality \\
\hline 1 & $1904-8-30$ & $31.0 \mathrm{~N}^{\circ}$ & $101.1 \mathrm{E}^{\circ}$ & 7.0 & $\begin{array}{l}\text { Daofu, } \\
\text { Sichuan }\end{array}$ \\
\hline 2 & $1908-2-9$ & $26.0 \mathrm{~N}^{\circ}$ & $100.0 \mathrm{E}^{\circ}$ & 7.3 & $\begin{array}{c}\text { Dali, } \\
\text { Yunnan }\end{array}$ \\
\hline 3 & $1913-12-21$ & $24.2 \mathrm{~N}^{\circ}$ & $102.5 \mathrm{E}^{\circ}$ & 7.0 & \begin{tabular}{|l|} 
Eshan, \\
Yunnan \\
\end{tabular} \\
\hline 4 & $1917-7-30$ & $28.4 \mathrm{~N}^{\circ}$ & $104.2 \mathrm{E}^{\circ}$ & 7.3 & $\begin{array}{c}\text { Dabeigu } \\
\text { an, } \\
\text { Yunnan }\end{array}$ \\
\hline 5 & $1923-3-24$ & $31.5 \mathrm{~N}^{\circ}$ & $101.0 \mathrm{E}^{\circ}$ & 7.2 & $\begin{array}{l}\text { Luhuo, } \\
\text { Sichuan }\end{array}$ \\
\hline 6 & $1925-3-16$ & $25.7 \mathrm{~N}^{\circ}$ & $100.4 \mathrm{E}^{\circ}$ & 7.0 & $\begin{array}{c}\text { Dali, } \\
\text { Yunnan }\end{array}$ \\
\hline 7 & $1933-8-25$ & $31.9 \mathrm{~N}^{\circ}$ & $103.4 \mathrm{E}^{\circ}$ & 7.5 & $\begin{array}{r}\text { Maoxian } \\
\text {, Sichuan }\end{array}$ \\
\hline 8 & $1941-5-16$ & $23.6 \mathrm{~N}^{\circ}$ & $99.4 \mathrm{E}^{\circ}$ & 7.0 & $\begin{array}{c}\text { Gengma, } \\
\text { Yunnan }\end{array}$ \\
\hline 9 & $1948-5-25$ & $29.5 \mathrm{~N}^{\circ}$ & $100.5 \mathrm{E}^{\circ}$ & 7.2 & \begin{tabular}{|l|} 
Litang, \\
Sichuan \\
\end{tabular} \\
\hline 10 & $1955-4-14$ & $30.0 \mathrm{~N}^{\circ}$ & $101.8 \mathrm{E}^{\circ}$ & 7.5 & \begin{tabular}{|c|} 
Ganzi, \\
Sichuan \\
\end{tabular} \\
\hline 11 & $1967-8-30$ & $31.6 \mathrm{~N}^{\circ}$ & $100.2 \mathrm{E}^{\circ}$ & 7.0 & \begin{tabular}{|l|} 
Luhuo, \\
Sichuan
\end{tabular} \\
\hline 12 & $1970-1-4$ & $24.1 \mathrm{~N}^{\circ}$ & $102.5 \mathrm{E}^{\circ}$ & 7.8 & $\begin{array}{c}\text { Tonghai, } \\
\text { Yunnan }\end{array}$ \\
\hline 13 & $1973-2-6$ & $31.4 \mathrm{~N}^{\circ}$ & $100.5 \mathrm{E}^{\circ}$ & 7.6 & \begin{tabular}{|l|} 
Luhuo, \\
Sichuan \\
\end{tabular} \\
\hline 14 & $1974-5-10$ & $28.2 \mathrm{~N}^{\circ}$ & $104.0 \mathrm{E}^{\circ}$ & 7.1 & $\begin{array}{c}\text { Dabeigu } \\
\text { an, } \\
\text { Yunnan }\end{array}$ \\
\hline \multirow{2}{*}{15} & $1976-5-29$ & $24.5 \mathrm{~N}^{\circ}$ & $98.9 \mathrm{E}^{\circ}$ & 7.3 & $\begin{array}{l}\text { Longling } \\
\text {, Yunnan }\end{array}$ \\
\hline & $1976-5-29$ & $24.5 \mathrm{~N}^{\circ}$ & $98.7 \mathrm{E}^{\circ}$ & 7.4 & $\begin{array}{l}\text { Longling } \\
\text {, Yunnan }\end{array}$ \\
\hline \multirow{2}{*}{16} & $1976-8-16$ & $32.8 \mathrm{~N}^{\circ}$ & $104.1 \mathrm{E}^{\circ}$ & 7.2 & \begin{tabular}{|l} 
Songpan, \\
Sichuan
\end{tabular} \\
\hline & $1976-8-23$ & $32.5 \mathrm{~N}^{\circ}$ & $104.2 \mathrm{E}^{\circ}$ & 7.2 & $\begin{array}{l}\begin{array}{c}\text { Songpan, } \\
\text { Sichuan }\end{array} \\
\end{array}$ \\
\hline 17 & $1988-11-6$ & $22.8 \mathrm{~N}^{\circ}$ & $99.6 \mathrm{E}^{\circ}$ & 7.4 & \begin{tabular}{|c|} 
Lincang, \\
Yunnan \\
\end{tabular} \\
\hline 18 & $1995-7-11$ & $22.0 \mathrm{~N}^{\circ}$ & $99.1 \mathrm{E}^{\circ}$ & 7.3 & $\begin{array}{c}\text { Menglia } \\
\text { n, } \\
\text { Yunnan }\end{array}$ \\
\hline 19 & $1996-2-3$ & $27.3 \mathrm{~N}^{\circ}$ & $100.3 \mathrm{E}^{\circ}$ & 7.0 & \begin{tabular}{|l|} 
Lijiang, \\
Yunnan \\
\end{tabular} \\
\hline 20 & $2008-5-12$ & $31.0 \mathrm{~N}^{\circ}$ & $103.4 \mathrm{E}^{\circ}$ & 8.0 & $\begin{array}{l}\text { Wenchu } \\
\text { an, } \\
\text { Sichuan }\end{array}$ \\
\hline 21 & $2013-4-20$ & $30.3 \mathrm{~N}^{\circ}$ & $103.0 \mathrm{E}^{\circ}$ & 7.0 & \begin{tabular}{|c|} 
Yaan, \\
Sichuan \\
\end{tabular} \\
\hline 22 & $2017-8-8$ & $33.2 \mathrm{~N}^{\circ}$ & $103.8 \mathrm{E}^{\circ}$ & 7.0 & $\begin{array}{c}\text { Aba, } \\
\text { Sichuan }\end{array}$ \\
\hline
\end{tabular}

The quarternary commensurability relational expression is $\mathrm{X} 22=\mathrm{X} 21+\Delta \mathrm{X}$, such that $\Delta \mathrm{X}=\mathrm{Xa}+\mathrm{Xb}-\mathrm{Xc}-$ $\mathrm{Xd}$ and $\mathrm{a}+\mathrm{b}=\mathrm{c}+\mathrm{d}$. Based on this relationship, earthquakes were found to occur 81 times in 2020, 74 times in 2019, 73 times in 2022, 71 times in 2018, 60 times in 2023 and 59 times in 2021. Finally, the pentabasic commensurability relational expression is $\mathrm{X} 22=\mathrm{Xa}+\mathrm{Xb}+$ $\mathrm{Xc}-\mathrm{Xd}-\mathrm{Xe}$, such that $\mathrm{a}+\mathrm{b}+\mathrm{c}-\mathrm{d}-\mathrm{e}=22$. The pentabasic commensurability results are as follows: earthquakes occurred 175 times in 2020,172 times in 2021, 164 times in 2019, 138 times in 2022 and 138 times in 2023.

Ternary commensurability is the main indicator when using the commensurability information to assess trends in earthquake occurrence. Quarternary and pentabasic commensurability are the further validations of the ternary commensurability, as the three represent independent methods. Combined with the results in Table 2, 2020 and 2021 were found to have the strongest signals, indicating that an $\mathrm{Ms} \geqslant 7.0$ earthquake will occur in the Sichuan-Yunnan region during one of these years.

Table 2. Commensurability frequencies of $M \geq 7.0$ earthquakes in the Sichuan-Yunnan region.

\begin{tabular}{|c|c|c|c|c|c|}
\hline Year & $\mathbf{2 0 1 9}$ & $\mathbf{2 0 2 0}$ & $\mathbf{2 0 2 1}$ & $\mathbf{2 0 2 2}$ & $\mathbf{2 0 2 3}$ \\
\hline Ternary & 3 & 6 & 13 & 4 & 9 \\
\hline Quarternary & 74 & 81 & 59 & 73 & 60 \\
\hline Pentabasic & 164 & 175 & 172 & 138 & 138 \\
\hline Year & $\mathbf{2 0 2 4}$ & $\mathbf{2 0 2 5}$ & $\mathbf{2 0 2 6}$ & $\mathbf{2 0 2 7}$ & $\mathbf{2 0 2 8}$ \\
\hline Ternary & 7 & 3 & 7 & 5 & 6 \\
\hline Quarternary & 45 & 42 & 30 & 32 & 29 \\
\hline Pentabasic & 132 & 96 & 113 & 100 & 80 \\
\hline
\end{tabular}

\subsection{Butterfly diagram trend assessment}

Based on the butterfly diagram of $\mathrm{Ms} \geqslant 7.0$ earthquakes constructed for the period since 1904 in the SichuanYunnan region, the annual time series was found to exhibit obvious temporal symmetry (Fig. 2). There are four groups of cycles related to 2020, which were Nos. 7 , 12,25 and 47 . Three cycles were also related to 2021, and these were Nos. 8, 25 and 47. The calculated results suggested that the random probability that an earthquake will occur in 2020 is $71.4 \%$, and in 2021 , it is $57.1 \%$. The confidence level for the earthquake prediction in 2020 was $68.2 \%$, and that in 2021 was $54.5 \%$. Therefore, it can be concluded that it is probable that there will be an $\mathrm{Ms} \geqslant 7.0$ earthquake in the Sichuan-Yunnan region in 2020 or 2021.

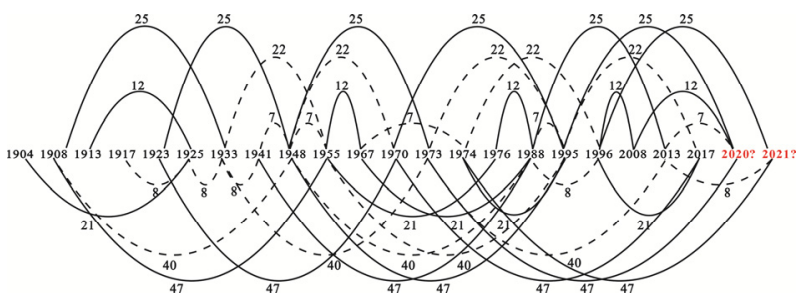

Fig. 2. Butterfly diagram of $M s \geq 7.0$ earthquake time series in the Sichuan-Yunnan region showing the years of earthquake occurrences and the earthquake cycles. 


\subsection{Commensurability structure system}

The commensurability structure is another expression of time symmetry, which is used to reflect the mutual ordering and temporal regularity of disaster events. Figure 3 is the commensurability structure system representative of the Sichuan-Yunnan region, which shows that there is obvious symmetry in the timing of earthquake occurrences. Laterally, the main cycles are 8(7)-20(21)-47, and the least important cycles are 7-42. In the vertical direction, the main cycles are $12-25$, and the least important cycles are 16-32-55. Based on the principles of time translation symmetry, it can be concluded that 2020 and 2021 are the possible years of earthquake occurrence. These results are consistent with those of the commensurability calculations and the butterfly diagram.

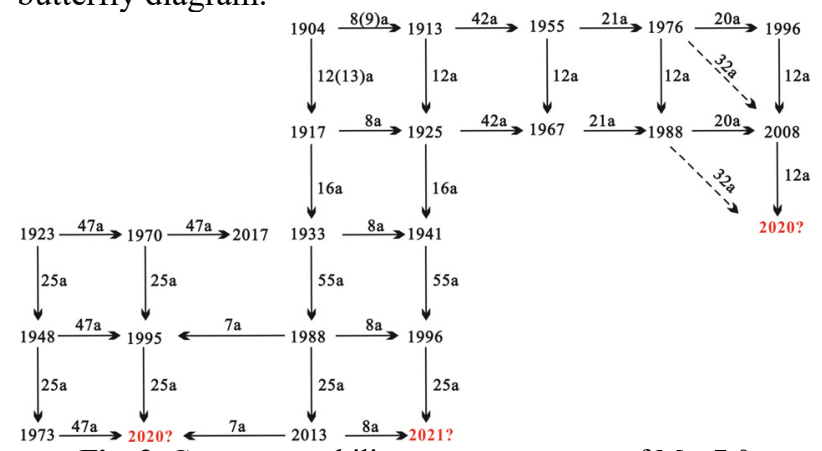

Fig. 3. Commensurability structure system of $\mathrm{Ms} \geq 7.0$ earthquakes in the Sichuan-Yunnan region showing the symmetry of earthquake cycles Spatial symmetry and trend assessment.

\section{Spatial Symmetry and Trend Assessment}

\subsection{Epicentre quadrilateral symmetric structure}

The spatial activity characteristics of $\mathrm{Ms} \geqslant 7.0$ earthquakes in the Sichuan-Yunnan region were analysed, and the epicentres were marked according to the annual time series of earthquake occurrence (Table 1). There were four times during which earthquakes occurred in 1976; two of them occurred in Longling and had epicentres located in the Tengchong-Longling seismic belt, while the other two occurred in Songpan and had epicentres located in the Songpan-Jiaochang seismic belt. As they were located in two different seismic belts, they were recorded as two earthquakes, one in each seismic belt. The four successive earthquakes were taken as a group and the epicentres were linked with a straight line (Fig. 4). The annual time series was divided into five, quadrilateral groups, and it was found that each quadrilateral group had a common spatial symmetry axis. A rectangular coordinate system was established, with $30^{\circ} \mathrm{N}$ as the vertical axis and $101.5^{\circ} \mathrm{E}$ as the horizontal axis. It can be seen in Figure 4 that the number of earthquakes on both sides of the coordinate axis was nearly the same: $10 \mathrm{Ms} \geqslant 7.0$ earthquakes occurred in the north and 12 occurred in the south when $30^{\circ} \mathrm{N}$ was taken as the boundary, and 10 earthquakes occurred in the east and 12 in the west when $101.5^{\circ} \mathrm{E}$ was used as the boundary.
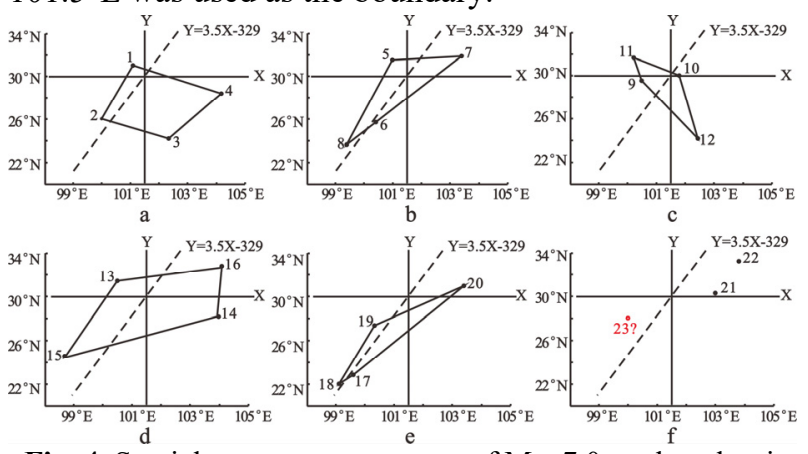

Fig. 4. Spatial symmetry structures of $M s \geq 7.0$ earthquakes in the Sichuan-Yunnan region: (a) group one; (b) group two; (c) group three; (d) group four; (e) group five; (f) group six.

By analysing the locations of epicentres, it was found that there was a northeast-southwest strike symmetry axis. As shown in Figure 4, the epicentres of each group were distributed evenly on both sides of the symmetry axis. The strike symmetry axis equation is $\mathrm{Y}=3.5 \mathrm{X}-329$. In group one (Fig. 4a), the No. 1 and No. 2 epicentres are above the symmetry axis, while Nos. 3 and 4 lie underneath it. The same pattern appeared in later groups. In group two (Fig. 4b), the No. 5 and No. 8 epicentres are above the line of symmetry, but Nos. 6 and 7 are under it. In group three (Fig. 4c), the No. 9 and No. 11 epicentres are above line of symmetry, but Nos. 10 and 12 are under it. In group four (Fig. 4d), the No. 13 and No. 15 epicentres are above the axis of symmetry, but Nos. 14 and 16 are under it. In group five (Fig. 4e), the No. 18 and No. 19 epicentres are above the line of symmetry, but Nos. 17 and 20 are beneath it. Group six is incomplete (Fig. 4f), and both the No. 21 and No. 22 epicentres are under the symmetry axis, suggesting that the next earthquake will occur on the upper side of the symmetry axis.

\subsection{Epicentre spatial migration characteristics of each group}

The epicentre migration in each group also exhibited obvious regularity (Table 3 ). In group one, the epicentre migrated in the order of 1-2-3-4 and the group epicentre migrated in an anticlockwise fashion. In groups two, three and four, the epicentres exhibited jumping migration along the diagonal direction. In each group, the first two epicentres and the last two epicentres were located at the four vertices of the spatial quadrilateral; the first and the third migration paths form the diagonal of the spatial quadrilateral, and thus, the migration was defined as jump-migration. In group two, the epicentre of Nos. 5 to 6 is the first migration, Nos. 7 to 8 is the third migration and the two epicentre migration paths form the diagonal of the spatial quadrilateral. The epicentre of Nos. 9 to 10 and Nos.11 to 12, and Nos. 13 to 14 and Nos. 15 to 16 are the first and third migration paths in group three and group four, respectively; their migration paths form the diagonals of the corresponding spatial quadrilaterals. In group five, the epicentre migrated in the order of 17-18-19-20 and the group 
epicentre migration was clockwise. Clockwise and anticlockwise migration was defined as sequentialmigration.

The overall direction of spatial migration in each group was consistent with the first epicentre migration path. In group one, the first migration moved anticlockwise from No. 1 to No. 2, which is in the same direction as for the group. In groups two, three and four, the first epicentre migrations were along the diagonal direction and consistent with the overall direction of each group. In group five, the first migration moved clockwise from No. 17 to No. 18, which is also the same direction as that of the group. Finally, the first epicentre migration of group six was anticlockwise from No. 21 to No.22, so the migration direction for the group was also anticlockwise.

In two adjacent groups, the second epicentre migration direction of the jump-migration group was consistent with that of the sequential-migration group. As shown in Table 3, group one exhibited sequentialmigration and was adjacent to the jump-migration of group two. The second epicentre migration in group two was anticlockwise, which is consistent with the overall migration direction of group one. Group five exhibited clockwise sequential-migration, which is consistent with the overall migration direction of the second migration direction of group four.

Table 3. The epicentre migration path in each group.

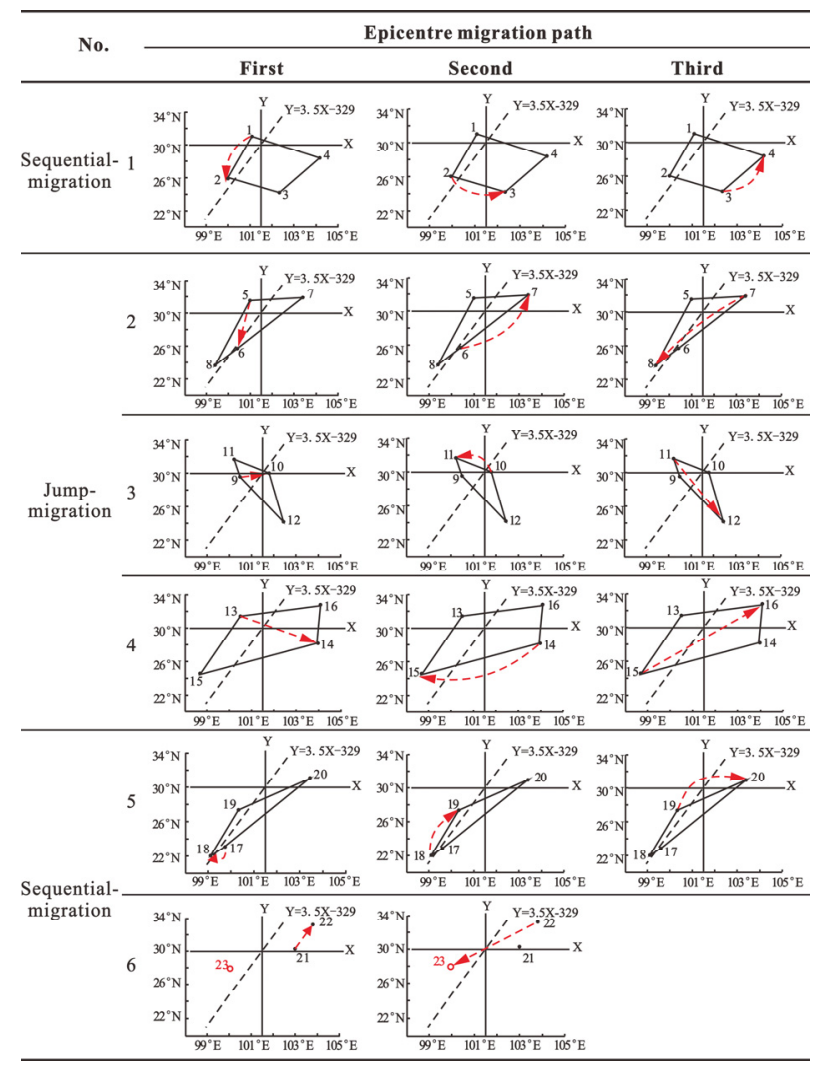

Analysis of the distributions of epicentres was based on the rectangular coordinate system established in section 4.1. In every group, the epicentre distribution in the quadrant within the rectangular coordinate system had uniform-discrete and concentrated-dispersion characteristics. 'Uniform-discrete' in this context means that each quadrant had one epicentre, and 'concentrateddispersion' means that if one quadrant had more than two epicentres, there was no epicentre within the following quadrant in the second migration direction of the group. The distribution of epicentres in groups three and four were uniform-discrete: in each quadrant, one earthquake occurred. The epicentres of group one, two and five were defined as concentrated-dispersion. In group one, there were two epicentres in the fourth quadrant; the second epicentre migration by No. 2 toward No. 3 was anticlockwise, and on the anticlockwise side of the fourth quadrant, was the first quadrant, which had no epicentre. In group two, there were two epicentres in the third quadrant; the second epicentre migration by No. 6 toward No. 7 was anticlockwise, and on the anticlockwise side of the third quadrant, was the fourth quadrant, which had no epicentre. In group five, there were three epicentres in the third quadrant, the second epicentre migration by No. 18 toward No. 19 was clockwise, and on the clockwise side of the third quadrant, was the second quadrant, which had no epicentre. Based on these results, the second epicentre migration of group six was anticlockwise, and there were two epicentres in the first quadrant, indicating that the next earthquake may occur in the third quadrant but not in the second quadrant.

\subsection{Latitudinal and longitudinal epicentre migration}

Figure 5a shows the $\mathrm{Ms} \geqslant 7.0$ earthquake epicentre migrations in the latitudinal direction and Figure $5 \mathrm{~b}$ shows those in the longitudinal direction within the Sichuan-Yunnan region. It can be seen in this figure that most of latitudinal migration of the epicentres is consistent with longitudinal migration. When epicentre migration was northward in latitude, it was also eastward in longitude, and when epicentre migration was southward in latitude, it was westward in longitude.

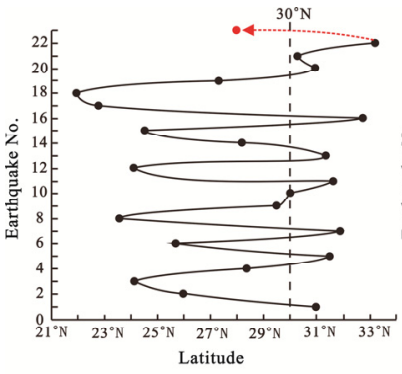

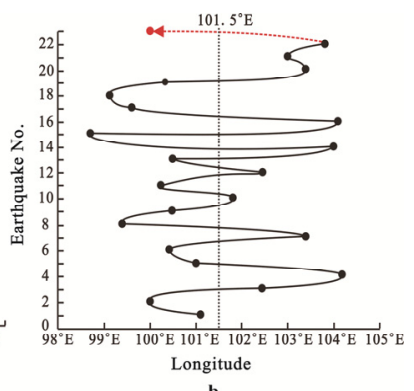

b
Fig. 5. The (a) latitudinal and (b) longitudinal epicentre migration of $M s \geq 7.0$ earthquakes in the Sichuan-Yunnan region.

The distribution of epicentres had an obvious symmetry axis over space, with a latitudinal axis at $30^{\circ} \mathrm{N}$. In five successive earthquakes, there were three times during which earthquakes occurred in the southern portion of the symmetry axis and another two times when earthquakes occurred in the northern portion of the symmetry axis. Except for the 10th earthquake in the 
annual time series, which occurred in Ganzi, Sichuan and had an epicentre at $30^{\circ} \mathrm{N}$, epicentres were distributed to the north or south of this symmetry axis in a regular fashion. In the first group of earthquake events, the 2 nd, 3rd and 4th epicentres were located south of $30^{\circ} \mathrm{N}$ and the $1 \mathrm{st}$ and 5 th epicentres were located north of $30^{\circ} \mathrm{N}$. In the second group of earthquake events, the 6th, 8th and 9th epicentres were located south of $30^{\circ} \mathrm{N}$ and the 7 th and 10th epicentres were located north of $30^{\circ} \mathrm{N}$. In the third group of earthquake events, the 12th, 14th and 15th epicentres were located south of $30^{\circ} \mathrm{N}$ and the 11 th and 13th epicentres were located north of $30^{\circ} \mathrm{N}$. In the fourth group of earthquake events, the $17 \mathrm{th}, 18 \mathrm{th}$ and 19th epicentres were located south of $30^{\circ} \mathrm{N}$ and the 16th and 20 th epicentres were located north of $30^{\circ} \mathrm{N}$. The $21 \mathrm{st}$ and 22nd were the last two times that $\mathrm{Ms} \geqslant 7.0$ earthquakes occurred in the last 117 years, and both of their epicentres were located north of $30^{\circ} \mathrm{N}$ latitude, suggesting that the next earthquake will occur south of $30^{\circ} \mathrm{N}$ latitude.

The longitudinal symmetry axis was at $101.5^{\circ} \mathrm{E}$, which exhibited similar characteristics to the latitudinal axis at $30^{\circ} \mathrm{N}$. In the first group of earthquake events, the $1 \mathrm{st}, 2 \mathrm{nd}$ and 5 th epicentres were located west of $101.5^{\circ} \mathrm{E}$ and the 3 rd and 4 th epicentres were located east of $101.5^{\circ} \mathrm{E}$. In the second group of earthquake events, the 6th, 8th and 9th epicentres were located west of $101.5^{\circ} \mathrm{E}$ and the 7 th and 10 th were located east of $101.5^{\circ} \mathrm{E}$. In the third group of earthquake events, the 11 th, 13 th and 15 th epicentres were located west of $101.5^{\circ} \mathrm{E}$ and the 12 th and 14 th were located east of $101.5^{\circ} \mathrm{E}$. In the fourth group of earthquake events, the 17 th, 18th and 19th epicentres were located west of $101.5^{\circ} \mathrm{E}$ and the 16th and 20th epicentres were located east of $101.5^{\circ} \mathrm{E}$. The fifth group began with the 21 st and 22 nd earthquakes, both of which were located east of $101.5^{\circ} \mathrm{E}$; therefore, the next earthquake should occur west of $101.5^{\circ} \mathrm{E}$. Combining these results, an $\mathrm{Ms} \geqslant 7.0$ earthquake should occur south of $30^{\circ} \mathrm{N}$ and west of $101.5^{\circ} \mathrm{E}$ in the Sichuan-Yunnan region.

\section{Conclusions}

The yearly information for Ms $\geqslant 7.0$ earthquakes in the Sichuan-Yunnan region over the last 117 years exhibits high commensurability. Based on ternary, quarternary and pentabasic commensurability calculations, it was found that an $\mathrm{Ms} \geqslant 7.0$ earthquake may occur in 2020 or 2021 in the Sichuan-Yunnan region. The random probability of an $\mathrm{Ms} \geqslant 7.0$ earthquake occurring in 2020 is $71.4 \%$ and in 2021 , the probability is $57.1 \%$. The prediction confidence level in 2020 is $68.2 \%$ and in 2021, it is $54.5 \%$. The results of analyses using a butterfly diagram were consistent with commensurability calculations.

The Ms $\geqslant 7.0$ earthquakes that have occurred within the last 117 years in the Sichuan-Yunnan region exhibit marked spatial symmetry. The spatial symmetry axis is northeast-southwest, with a latitude of $30^{\circ} \mathrm{N}$ and a longitude of $101.5^{\circ} \mathrm{E}$. The next epicentre may migrate toward the southwest (i.e., south of $30^{\circ} \mathrm{N}$ and west of $101.5^{\circ} \mathrm{E}$ ). Four successive earthquakes were regarded as one group based on the $\mathrm{Ms} \geqslant 7.0$ earthquake annual time series. The epicentre spatial migration path in each group exhibited separate jump-migrations and sequentialmigrations. The spatial distribution of epicentres in each group included both uniform-discrete and concentrateddispersion in symmetry axis quadrants. Furthermore, the first epicentre migration direction for each group was consistent with the overall spatial migration direction. The second epicentre migration direction of the jumpmigration group was consistent with the overall epicentre migration direction of the adjacent sequentialmigration group.

Funding: This research was supported by the National Natural Science Foundation of China (grant number 41877519)

\section{References}

1. J. P. Yan, Space-time symmetry of earthquakes (Science Press Ltd, Beijing, 2016)

2. G. H. Liang, Distribution of seismic zones in China. Anhui Sci Technol 6, 12 (2008)

3. X. Y. Zhao, R. B. Yu, Introduction to earthquake (Tsinghua University Press, Beijing, 2013)

4. W. B. Weng, Commensurability. Acta Geophy Sin 2, $24(1981)$

5. X. J. Cui, J. P. Yan, Z. B. Dong, L. Pang, The active pattern and future trend of earthquakes with $\mathrm{Ms} \geq 7.0$ in Philippines in recent 50 years. South China $J$ Seismol 2, 33 (2013)

6. J. F. Jin, S. Y. Yin, J. P. Yan, Symmetry and tendency judgment of $\mathrm{Ms} \geq 8.0$ strong earthquake in Chile. Geod Geodyn 1, 5 (2014)

7. S. S. Li, J. P. Yan, Space-time symmetry of $M s \geq 8$ earthquake in north-western pacific plate subduction. Prog Geophys 3, 27 (2012)

8. X. X. Long, J. P. Yan, H. Sun, Z. Z. Wang, Study on earthquake tendency in Sichuan-Yunnan region based on commensurability. J Catastr 3, 21 (2006)

9. J. P. Yan, N. Yan. Probability and verification of constructing an earthquake predicting system. $J$ Shaanxi Norm Univ 5, 37 (2008)

10. L. L. Zhang, J. Dong, J. P. Yan, T. Wang, The symmetry and the tendency judgment of $\mathrm{Ms} \geq 6.6$ earthquakes in southern Tibet. Plateau Earthq Res 3, 24 (2012)

11. Y. L. Liu, J. P. Yan, The model and effect test about the trend judgment of natural disasters. J Shaanxi Norm Univ 5, 43 (2015)

12. Y. J. Su, J. Z. Qin, Strong earthquake activity and relation to regional new tectonic movement in Sichuan-Yunnan region. Earthq Res China 6, 17 (2001) 
13. Y. Sun, Z. H. Wu, M. J. An, C. X. Long, Activity characteristics of primary active faults in YunnanSichuan area and their seismic activity in the past. China Earthq Eng J 2, 36 (2014)

14. S. Q. Qin, L. Xue, G. L. Li, X. H. Pan, Reanalysis of the future earthquake situation for some seismic zones in the Sichuan and Yunnan regions. Prog Geophys 4, 28 (2013)

15. Z. P. Song, G. M. Zhang, J. Liu, J. Y. Yin, Y. Xue, X. Y. Song, Global earthquake catalog (Seismological Press, Beijing, 2011)

16. W. B. Weng, Fundamentals of forecasting theory (Petroleum Industry Press, Beijing, 1984)

17. M. Li, Z. H. Zou, P. J. Shi, J. A. Wang, World earthquake disaster risk assessment. $J$ Nat Disasters 5, 24 (2015) 